\title{
Inhibition of Streptococcus mutans biofilms with bacterial-derived outer membrane vesicles
}

\author{
Yihui Wang ${ }^{1}$, Joseph P. Hoffmann', Sarah M. Baker', Kerstin Höner zu Bentrup', William C. Wimley², \\ Joseph A. Fuselier ${ }^{3}$, Jacob P. Bitoun ${ }^{1 *}$ and Lisa A. Morici ${ }^{*}$
}

\begin{abstract}
Background: Biofilms are microbial communities surrounded by a self-produced extracellular matrix which protects them from environmental stress. Bacteria within biofilms are 10- to 1000-fold more resistant to antibiotics, making it challenging but imperative to develop new therapeutics that can disperse biofilms and eradicate infection. Gramnegative bacteria produce outer membrane vesicles (OMV) that play critical roles in communication, genetic exchange, cargo delivery, and pathogenesis. We have previously shown that OMVs derived from Burkholderia thailandensis inhibit the growth of drug-sensitive and drug-resistant bacteria and fungi.

Results: Here, we examine the antibiofilm activity of Burkholderia thailandensis OMVs against the oral biofilmforming pathogen Streptococcus mutans. We demonstrate that OMV treatment reduces biofilm biomass, biofilm integrity, and bacterial cell viability. Both heat-labile and heat-stable components, including 4-hydroxy-3-methyl-2(2-non-enyl)-quinoline and long-chain rhamnolipid, contribute to the antibiofilm activity of OMVs. When OMVs are co-administered with gentamicin, the efficacy of the antibiotic against S. mutans biofilms is enhanced.
\end{abstract}

Conclusion: These studies indicate that bacterial-derived OMVs are highly effective biological nanoparticles that can inhibit and potentially eradicate biofilms.

Keywords: Biofilm, Nanoparticle, Bacteria, Burkholderia

\section{Background}

Biofilms are surface-associated microbial communities surrounded by a complex and highly viscous extracellular polymeric substance (EPS) composed of polysaccharides, proteins, lipids and other microbial-derived products. According to the National Institutes of Health, biofilmforming pathogens are responsible for $80 \%$ of human infections [1, 2]. Biofilm-related infections often result from microbial colonization of soft tissues or medical implants and can manifest as persistent or chronic diseases [3]. The

\footnotetext{
*Correspondence: jbitoun@tulane.edu; Imorici@tulane.edu

'Department of Microbiology and Immunology, Tulane University School of Medicine, 1430 Tulane Ave., SL-38, LA 70112-2699 New Orleans, USA

Full list of author information is available at the end of the article
}

gel-like EPS encases and protects the microbes from antimicrobials and host immune defense mechanisms, severely obstructing the eradication of biofilm-forming pathogens. Previous work indicates that bacteria within biofilms are 10- to 1000-fold more resistant to common antibiotics [2]. This is due to a number of resistance mechanisms including poor biofilm penetration by antimicrobial agents $[4,5]$; metabolically-inactive, dormant, or persister cell bacterial phenotypes with reduced drug susceptibility [6, 7]; and a variety of other bacterial adaptive responses $[2,8,9]$. For these reasons, new therapeutic strategies that can both inhibit and disrupt bacterial biofilms are needed to prevent chronic infections. Various approaches, including inhibitors of EPS formation [10, 11], 
biofilm-degrading enzymes [12, 13], quorum sensing inhibitors [14], and vaccination [15, 16] are being pursued but none are available for clinical use thus far [17].

Gram-negative bacteria naturally and constitutively shed outer membrane vesicles (OMV) from their surface in an active and selective response to extracellular stressors $[18,19]$. OMV nanoparticles range in size between 20 and $450 \mathrm{~nm}$. OMVs contain numerous components including small molecules [20], proteins [21], lipids [22], polysaccharides [23], and RNA/DNA [24, 25] that are embedded within the OMV bi-layered membrane or within the vesicle lumen. OMVs serve various roles in nature, including but not limited to, cargo delivery, cell to cell communication, and genetic exchange [26]. OMVs are ubiquitous and an important particulate constituent of Gram-negative and polymicrobial biofilms [27]. In recent years, several groups, including ours, have reported on the potent antimicrobial activity of OMVs mediated by small molecules, surfactants, and enzymes [28-33]. Given their antimicrobial activity and natural occurrence in bacterial biofilms, we hypothesized that OMVs could potentially be useful in treating or disrupting biofilms formed by competitor bacteria. In previous work, we showed that OMVs derived from Burkholderia thailandensis inhibit the growth of drug-sensitive and drug-resistant bacteria and fungi. B. thailandensis is an oxidase-positive, Gram-negative rod that is considered largely non-pathogenic to humans. B. thailandensis contains a mixture of tetra- and penta-acylated lipid A species that dampens lipopolysaccharide (LPS)-mediated endotoxicity [34]. A number of antimicrobial compounds, including peptidoglycan hydrolases, 4-hydroxy3-methyl-2-(2-non-enyl)-quinoline (HMNQ), and longchain rhamnolipid are present in or tightly associate with $B$. thailandensis OMVs [35].

Cariogenic plaque is one of the best-characterized biofilms known to develop within the human body. Although well-described in the literature, it is still a neglected topic and major health problem affecting 60 $90 \%$ of children and most adults globally [36]. As one of the most cariogenic microorganisms in dental biofilms, Streptococcus mutans is capable of using dietary carbohydrates, especially sucrose, to produce organic acids that demineralize tooth enamel and generate robust biofilms with glucan-based EPS. These biofilms serve as important virulence factors for supporting the bacterial community on dental surfaces $[37,38]$. In addition to dental caries, $S$. mutans is also one of the common causes of endocarditis [39]. Furthermore, S. mutans is a model Gram-positive organism that can help provide a better understanding of biofilm biology, genetics, and physiology for other closely-related streptococcal as well as other Gram-positive species [40]. In this study, we evaluated the antimicrobial and antibiofilm activity of $B$. thailandensis OMVs against the robust biofilm-forming, oral pathogen S. mutans. Here we show that OMVs exhibit potent bactericidal activity against $S$. mutans and reduce total biomass, biofilm integrity, and cell viability when applied to pre-formed S. mutans biofilms. Previously identified heat-stable components of OMVs, HMNQ and rhamnolipid, contribute to their antimicrobial and antibiofilm activities. We also observed increased efficacy of the antibiotic gentamicin when it was co-delivered with OMVs. These findings suggest that OMVs may represent a natural resource to combat biofilm-forming microorganisms.

\section{Results}

Burkholderia thailandensis OMVs exhibit antimicrobial activity against $\mathrm{S}$. mutans

OMVs used for the current study were produced from multiple, independent batches and characterized as previously described [35]. We first screened OMV antimicrobial activity against $S$. mutans grown on agar plates and in broth cultures. OMVs inhibited $S$. mutans growth on agar whereas the PBS control treatment did not (Fig. 1 A). We used a Chi-squared test to compare curves at all time points (see Methods). Based on this analysis, growth of $S$. mutans in planktonic cultures was significantly inhibited by OMVs compared to control treatment, and OMV-mediated inhibition was dosedependent (Fig. 1B).

\section{OMVs inhibit S. mutans biofilms and planktonic cultures} in a time- and dose-dependent manner

We next evaluated whether OMVs could disrupt biofilm formation by S. mutans. S. mutans was cultured in biofilm medium containing glucose and sucrose (BMGS) on glass slides for 3 days (Fig. 2 A) then treated them with OMVs, gentamicin, or PBS. All cultures were run in parallel and compared to planktonic overnight cultures receiving the same treatments. The inhibition of $S$. mutans biofilm and planktonic cultures was readily observed within $3 \mathrm{~h}$ of OMV treatment with greater than 10-fold reduction in CFU. After $6 \mathrm{~h}$, both biofilm and planktonic cultures treated with OMVs showed 1000-fold reduction in CFU compared to control-treated cultures at the same time-point (Fig. 2B and C). OMV antimicrobial activity was less effective against $S$. mutans biofilms compared to planktonic cultures at $6 \mathrm{~h}$ post-treatment. Strikingly, both concentrations tested (50 and $100 \mu \mathrm{g} / \mathrm{ml}$ ) OMVs killed all $S$. mutans planktonic and biofilm cultures after 24 h compared to control-treated cultures that still contained more than $10^{7} \mathrm{CFU} / \mathrm{mL}$ viable cells. In pilot studies, concentrations less than $50 \mathrm{ug} / \mathrm{ml}$ were not effective against biofilms when administered as a single dose. Gentamicin at a concentration of $800 \mu \mathrm{g} / \mathrm{mL}$ failed to 


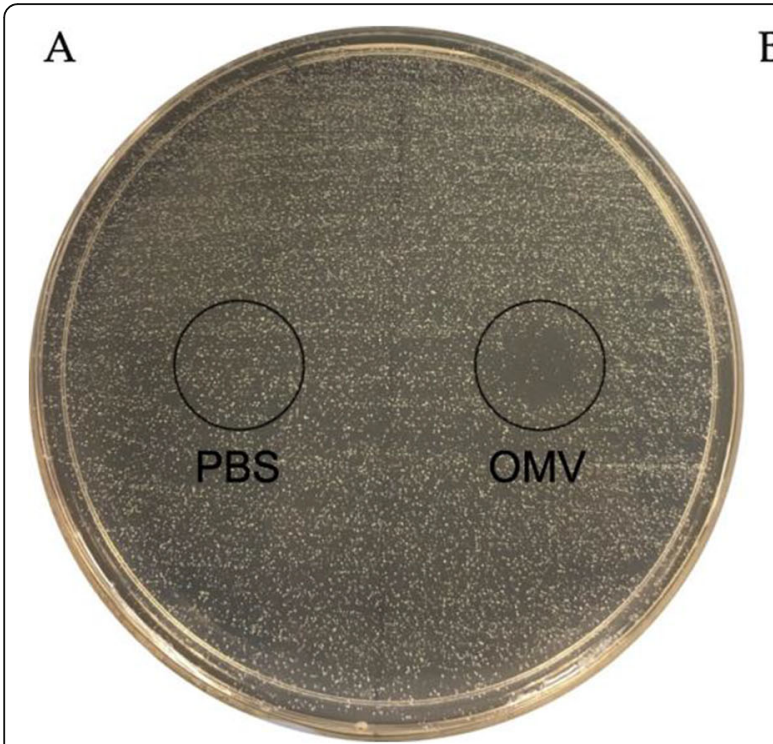

B

Fig. 1 OMVs inhibit the growth of S. mutans. The antimicrobial activity of OMVs against S. mutans was evaluated on (A) agar plates and in (B) planktonic cultures. PBS (left side, $10 \mu \mathrm{L}$ ) or OMVs (right side, $10 \mu \mathrm{g}$ suspended in $10 \mu \mathrm{L}$ PBS) were spot plated onto agar streaked with $\mathrm{S}$. mutans and incubated for $24 \mathrm{~h}$ to determine growth inhibition. For planktonic cultures, overnight cultures of $\mathrm{S}$. mutans were diluted 1:1000 in broth and treated with $0.2,1$, or $2 \mu \mathrm{g}$ OMVs or PBS in a total volume of $100 \mu \mathrm{L}$. $\mathrm{OD}_{600}$ was monitored for up to $12 \mathrm{~h}$. The curves were compared using a Chi-squared test, see Methods. (**** $p<0.0001)$

clear the bacteria, with more than $10^{3} \mathrm{CFU} / \mathrm{mL}$ of viable planktonic cells and $10^{5} \mathrm{CFU} / \mathrm{mL}$ of viable biofilm cells remaining after $24 \mathrm{~h}$ of treatment (Fig. $2 \mathrm{~B}$ and $\mathrm{C}$ ). The Chi-squared test showed highly significant differences between the curves. OMVs displayed potent bactericidal activity against both $S$. mutans planktonic and biofilm cultures in a time- and dose-dependent manner. Notably, while OMVs and gentamicin were both efficient in killing planktonic cells, S. mutans biofilms were significantly more susceptible to OMVs than gentamicin.
OMVs reduce total biomass, biofilm integrity, and cell viability in S. mutans biofilms

To further evaluate OMV-mediated disruption of preformed, intact $S$. mutans biofilms, we utilized fluorescent confocal microscopy combined with COMSTAT analysis. Biofilms of $S$. mutans were grown on chamber slides for 3 days then treated with PBS or increasing doses of OMVs for $24 \mathrm{~h}$ prior to imaging. Biofilms were stained with SYTO 9 to examine total biomass and propidium iodide (PI) to determine dead cell biomass.

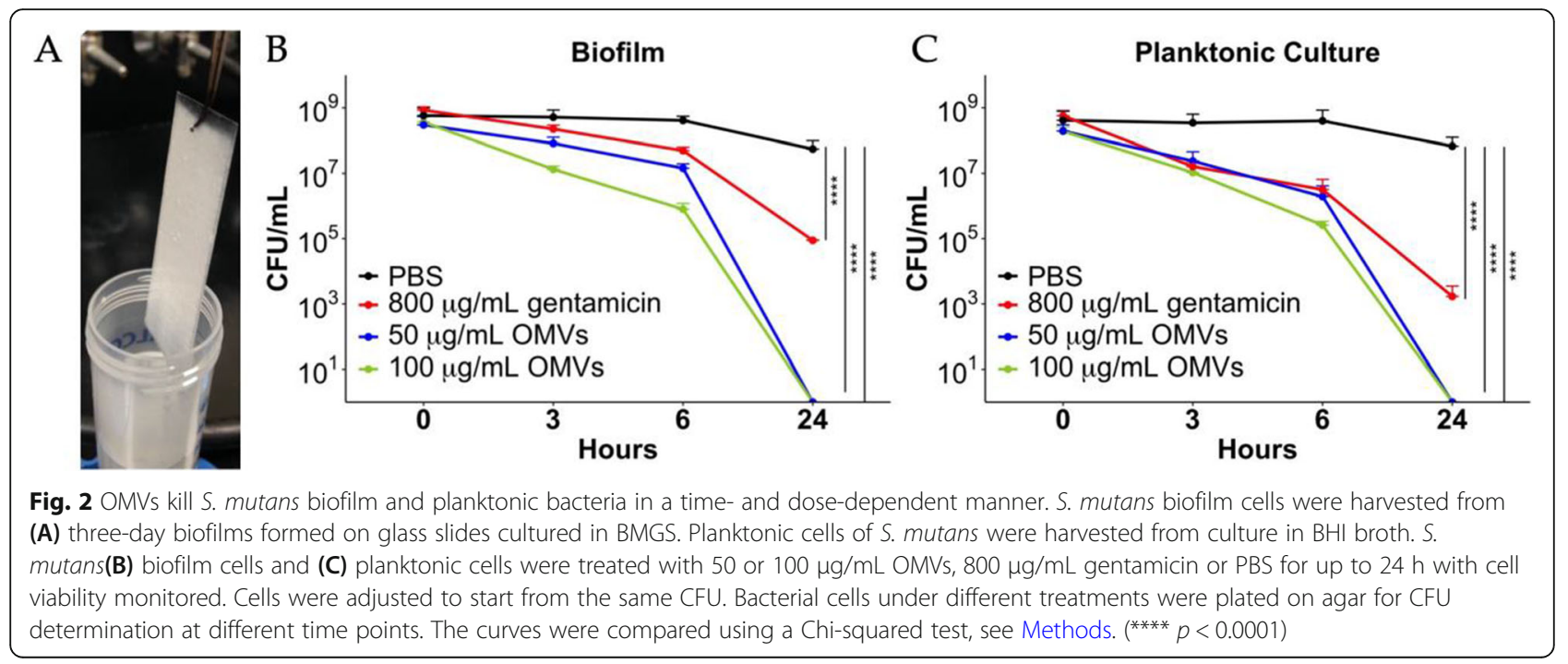


Remarkably, increasing concentrations of OMVs led to a reduction in total biomass (green fluorescence) in $S$. mutans biofilms as well as an increase in the biomass of dead cells (red fluorescence; Fig. 3 A-D). There was also an observable decrease in biofilm thickness after OMV treatments (Side bars, Fig. 3 A-C). Furthermore, the lack of red fluorescence at the bottom of OMV-treated biofilms suggests an inability to fully penetrate the biofilm, which is one of the obstacles in developing effective antibiofilm agents. COMSTAT analysis indicated that OMVs reduced biofilm thickness and integrity in a dosedependent manner (Fig. 3E). The significant increase in roughness coefficient is further evidence of an overall deterioration of biofilm integrity (Fig. 3 F) [35, 41]. Scanning electron micrographs of OMV-treated biofilms corroborated the COMSTAT analyses by revealing differences in biofilm architecture. In particular, OMVtreated biofilms had a diminished presence of extracellular material and structures compared to healthy control biofilms (Supplemental Figure 1).
Heat-inactivated OMVs exhibit antimicrobial and antibiofilm activity against $\mathrm{S}$. mutans

In previous work, we demonstrated that $B$. thailandensis OMVs contain heat-labile peptidoglycan hydrolases that contribute to their antimicrobial activity against Staphylococcus aureus by degrading the cell wall [35]. However, when OMVs were applied to purified $S$. mutans peptidoglycan, OMVs failed to degrade the peptidoglycan (not shown). This suggested that OMV antimicrobial activity against $S$. mutans does not depend on peptidoglycan degrading enzymes. To further examine this, OMVs were heat-inactivated to destroy enzymatic activity. When applied to $S$. mutans planktonic cultures, heat-inactivated OMVs still significantly inhibited the growth of three different $S$. mutans strains, including low passage isolates, albeit to a lesser extent than native OMVs (Fig. 4). To investigate the antibiofilm activity of heat-inactivated OMVs, S. mutans biofilms were preformed on chamber slides then treated with PBS, $100 \mu \mathrm{g} / \mathrm{mL}$ heat-inactivated OMVs, or $100 \mu \mathrm{g} / \mathrm{mL}$ native

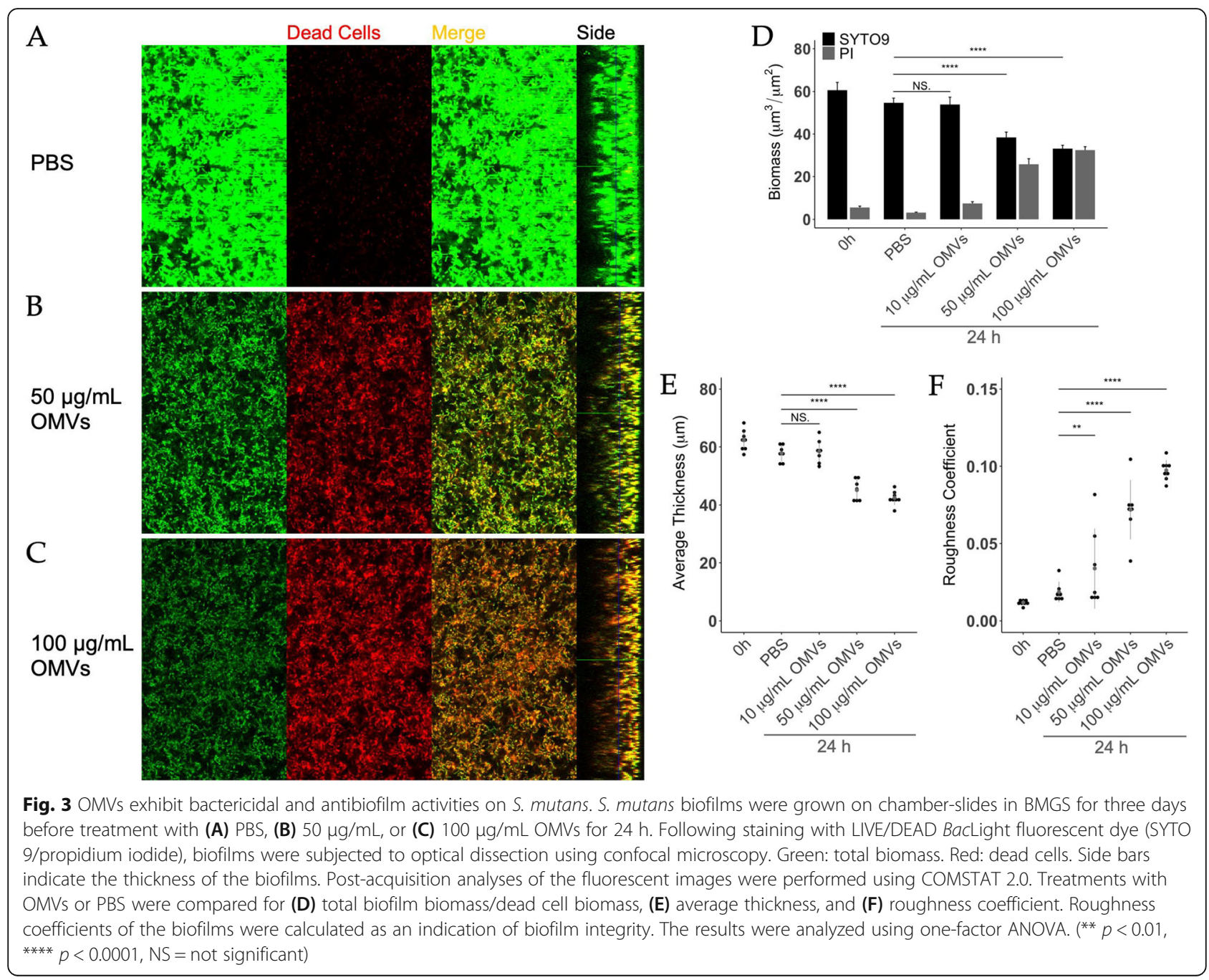



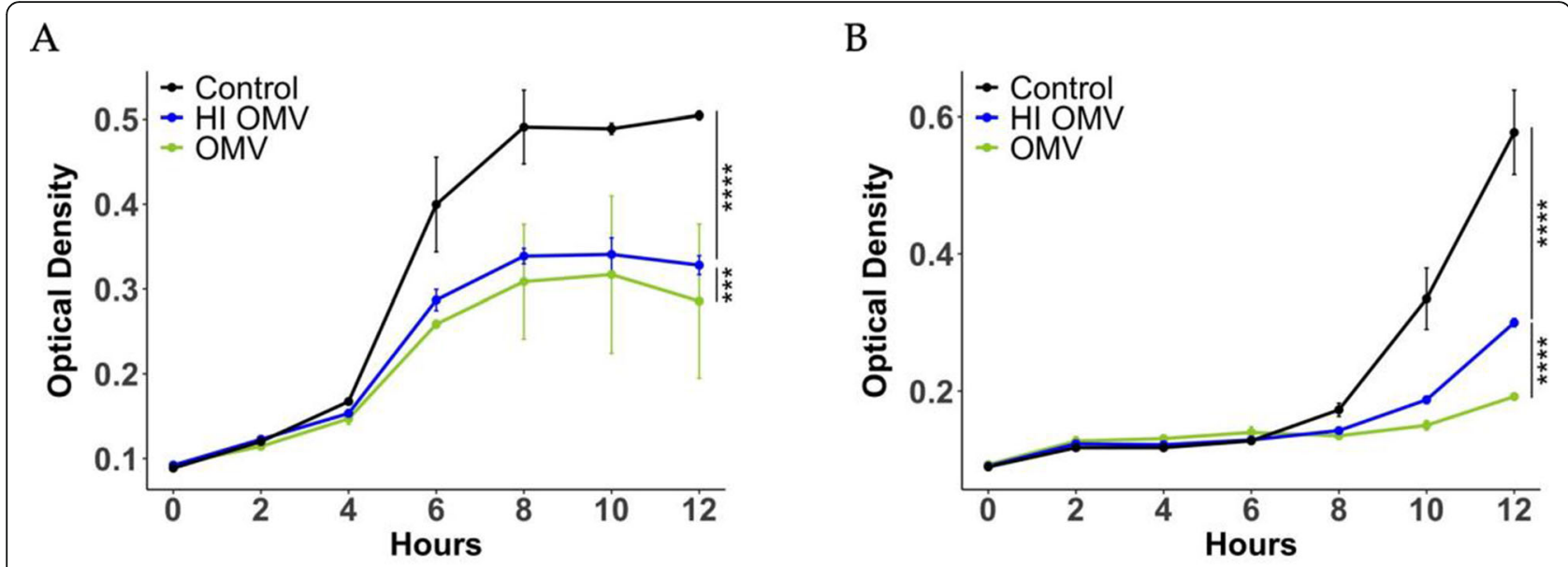

C

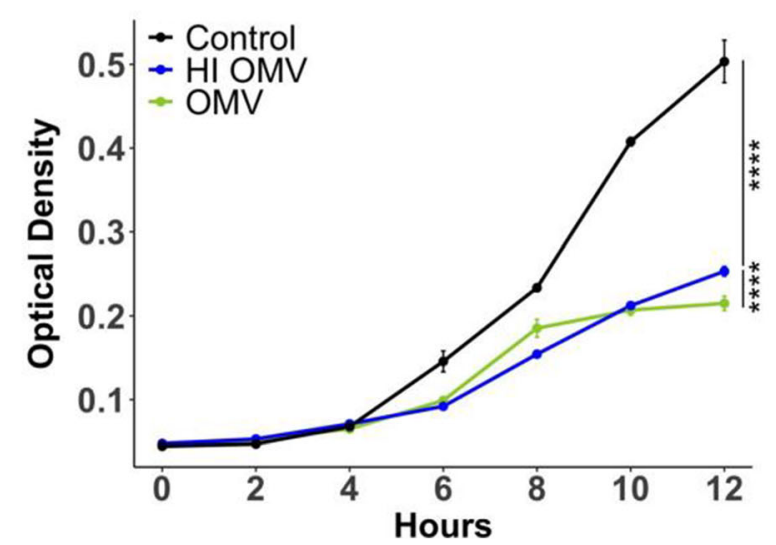

Fig. 4 Heat-inactivated OMVs display antimicrobial activity. Heat-inactivated OMVs inhibit the growth of S. mutans(A) UA159 strain (B) Clarke strain and (C) OMZ175 strain. Overnight cultures of S. mutans were diluted 1:100 in broth and treated with PBS, $2 \mu \mathrm{gg}$ OMVs, or $2 \mu \mathrm{g}$ heat-

inactivated OMVs in a total volume of $100 \mu \mathrm{L}$. OD 600 was monitored for up to $12 \mathrm{~h}$. The curves were compared using a Chi-squared test, see Methods. $\left.{ }^{* * *} p<0.001,{ }^{* * * *} p<0.0001\right)$

OMVs. Compared to PBS-treated control, treatment with heat-inactivated OMVs significantly decreased the average thickness and increased the dead cell ratio of pre-formed biofilms but did not affect the total biomass or roughness coefficient (Fig. 5). Thus, both heat-labile and heat-stable components of OMVs appear to contribute to anti-biofilm activity (Fig. 5).

\section{Rhamnolipid and HMNQ exhibit bactericidal and antibiofilm activity against $\mathrm{S}$. mutans}

Previously, we identified the heat-stable components, rhamnolipid and HMNQ, that contributed to B. thailandensis OMV-mediated antimicrobial activity against various bacteria and fungi, including drug-resistant pathogens [35]. Next, we evaluated the antimicrobial activity of purified rhamnolipid and HMNQ on planktonic S. mutans. The purified compounds were added to broth cultures of $S$. mutans as was done for OMVs using concentrations previously shown to be effective against other bacteria [35]. Rhamnolipid and HMNQ significantly inhibited the growth of the bacteria (Fig. 6). When applied to preformed S. mutans biofilms, rhamnolipid (Fig. 7B) and HMNQ (Fig. 7 C) significantly decreased the total biomass and biofilm thickness (Fig. 7E,G) and increased the ratio of dead cells in the biofilms as well as the roughness coefficient (Fig. 7 F,H), as compared to PBS control (Fig. 7 A, E-H). No additive effect was observed when $S$. mutans biofilms were treated with a mixture of HMNQ and rhamnolipid (Fig. 7D-H).

\section{OMVs enhance antibiotic efficacy against S. mutans biofilms}

Several strategies have been proposed to target drugresistant biofilm-related infections including combination therapies. To determine if OMVs could enhance antibiotic efficacy, we examined the effect of OMVs with gentamicin, which is commonly used in combination with other antibiotics against S. mutans infections [42]. We first established that the minimal inhibitory concentration (MIC) for gentamicin against $S$. mutans biofilms 


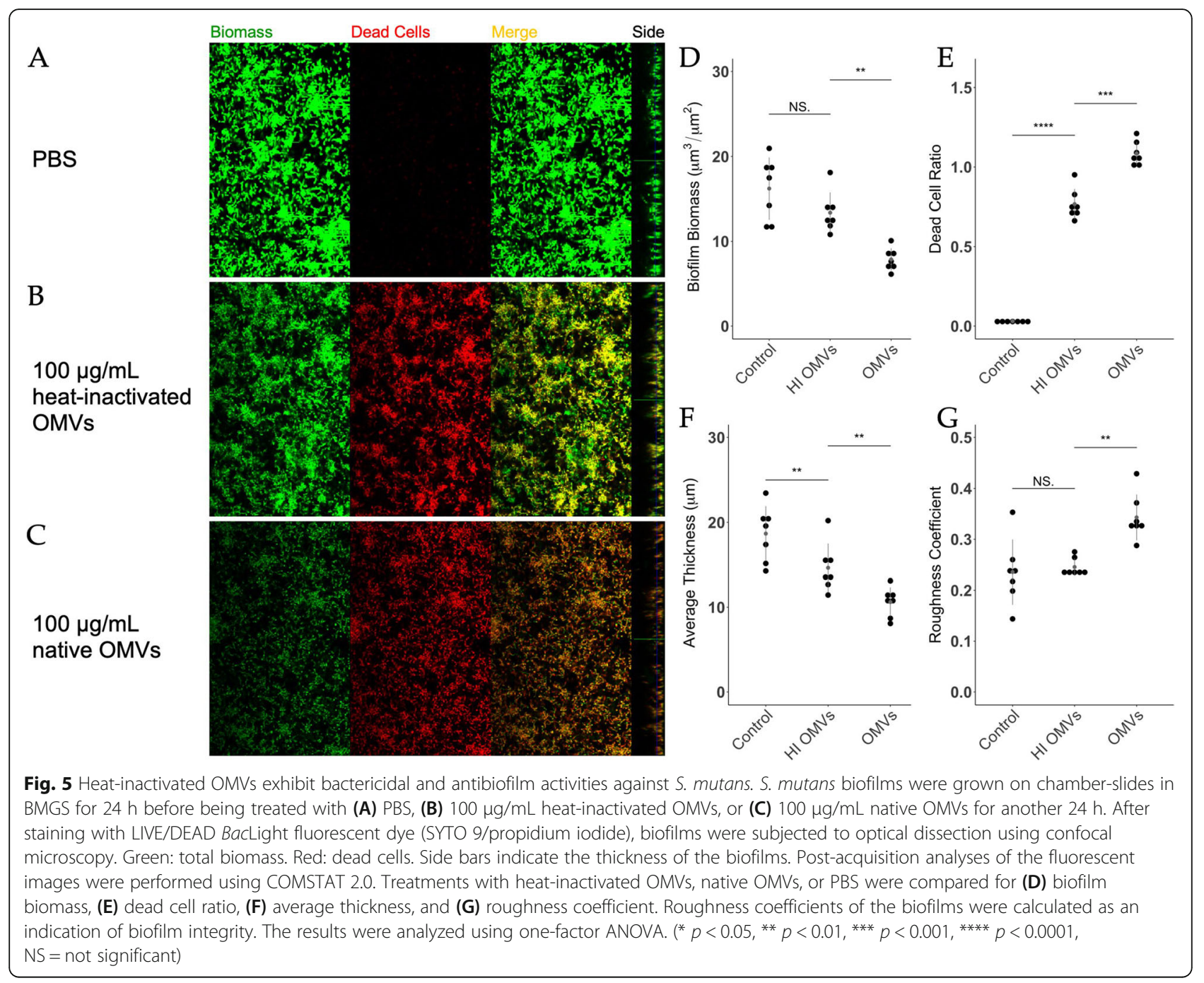

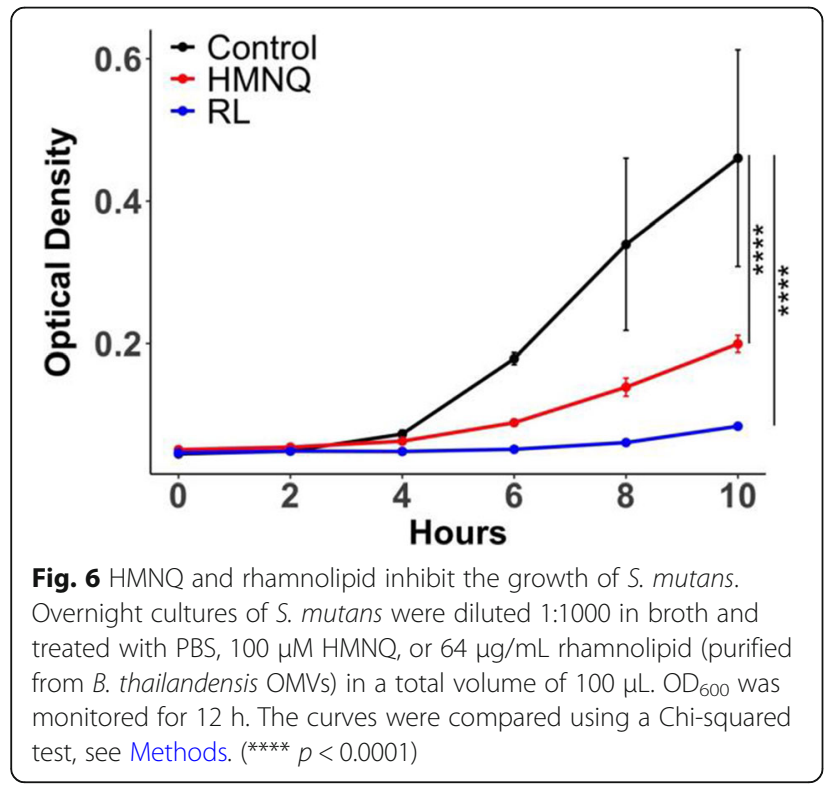

(MIC-B) was 7-fold higher than the MIC for planktonic cultures (MIC-P) (Table 1). When the antibiotic treatment was supplemented with sub-inhibitory concentrations of OMVs at 5,10 , and $20 \mu \mathrm{g} / \mathrm{mL}$, the MIC-B of gentamicin decreased by 2-, 4-, and 14-fold (Table 1), respectively, indicating an enhanced treatment effect upon co-administration with OMVs.

\section{Discussion}

In this study, we investigated the antimicrobial activity of $B$. thailandensis OMVs against a well-characterized biofilm-forming pathogen S. mutans. S. mutans forms highly robust biofilms when cultured in BMGS, allowing us to evaluate the antibiofilm properties of OMVs in this well-established model system. We show that OMVs are bactericidal against both planktonic and pre-formed $S$. mutans biofilms. OMV treatment reduced the overall biomass, biofilm integrity, and cell viability and altered the cellular morphology of $S$. mutans biofilm cells in a dose-dependent manner. Heat-inactivation of OMVs 


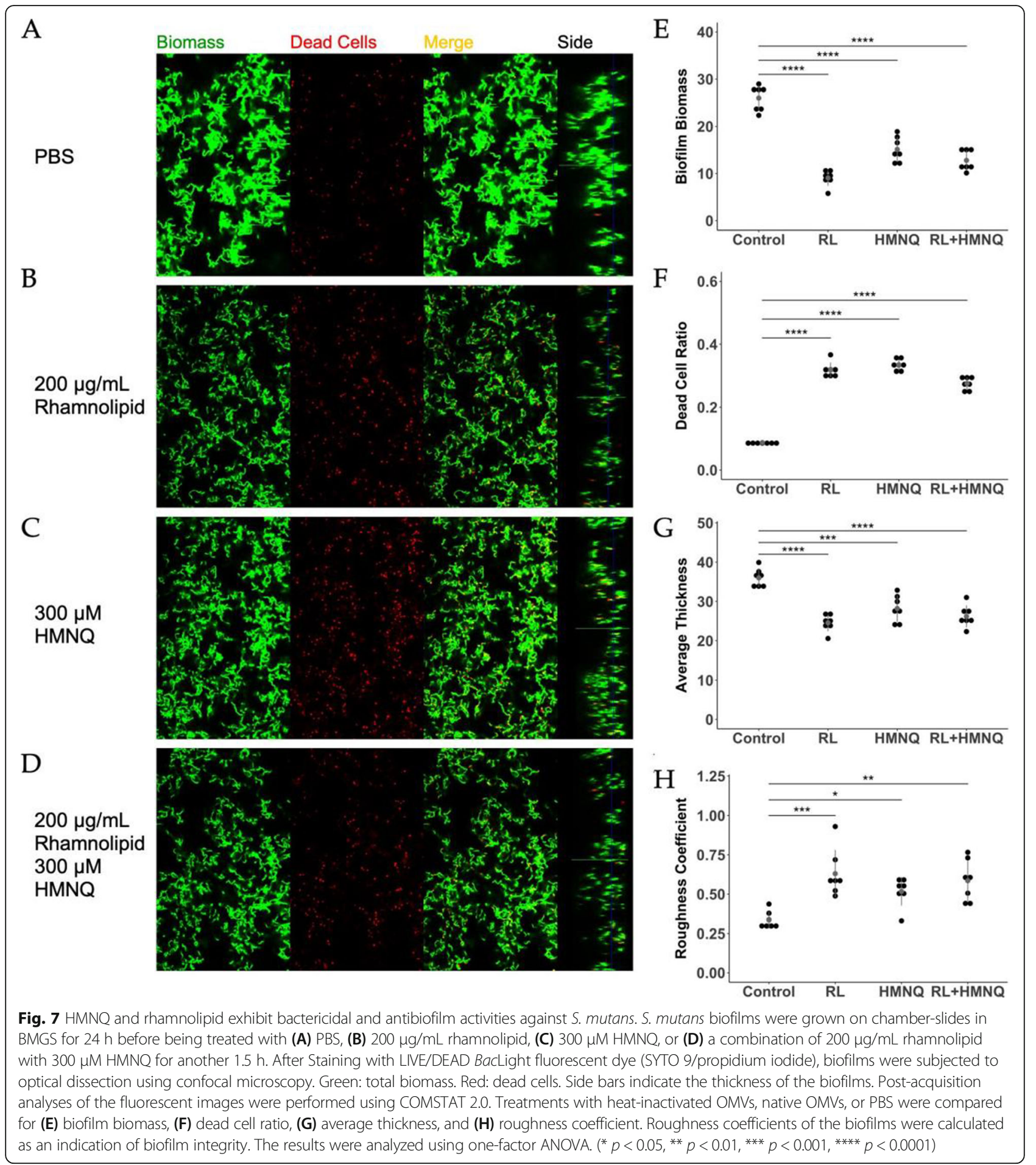

partially reduced the effect, suggesting that heat-labile components contribute to the disruption of $S$. mutans biofilms. It appears that peptidoglycan hydrolases present in the OMVs do not contribute to the antimicrobial activity against $S$. mutans since OMVs failed to degrade purified $S$. mutans peptidoglycan. This is in contrast to our previous observations that demonstrated
OMVs degraded peptidoglycan derived from $S$. aureus [35]. Peptidoglycan is the major component of the bacterial cell wall and is quite diverse in terms of sugar and peptide composition and length among bacterial species [43], which could potentially explain the inability of peptidoglycan hydrolases from $B$. thailandensis OMVs to recognize $S$. mutans. Proteomic analysis identified more 
Table 1 B. thailandensis OMVs enhance efficacy of gentamicin against $S$. mutans biofilms

\begin{tabular}{|c|c|c|c|c|}
\hline \multirow{2}{*}{$\begin{array}{l}\text { Gentamicin } \\
\text { MIC ( } \mu \mathrm{g} / \\
\mathrm{mL})\end{array}$} & \multicolumn{4}{|c|}{ OMVs $(\mu \mathrm{g} / \mathrm{mL})$} \\
\hline & 0 & 5 & 10 & 20 \\
\hline Biofilm & 141.42 & 62.98 & 35.36 & 9.92 \\
\hline Planktonic & 20.00 & - & - & - \\
\hline
\end{tabular}

${ }^{1}$ Planktonic cultures and biofilms of $S$. mutans were treated with 2-fold serial dilutions of gentamicin alone or gentamicin combined with $5,10,20 \mu \mathrm{g} / \mathrm{mL}$ OMVs for $24 \mathrm{~h}$. Fresh BHI was added and incubated for another $24 \mathrm{~h}$ to allow the detachment of viable cells within biofilms. $\mathrm{OD}_{600}$ was measured before and after the incubation to show the inhibition of bacterial growth. MICs were calculated as the geometric mean from the replicates

than one hundred proteins present in B. thailandensis OMVs (data not shown), and it is plausible that one or more of these contribute to OMV antimicrobial activity, warranting further study.

We previously identified HMNQ and rhamnolipid as broad-spectrum antimicrobial compounds that were present in B. thailandensis OMVs [35]. Here, were show that both of these compounds exhibit antimicrobial and antibiofilm activity against $S$. mutans. HMNQ is the dominant form of 4-hydroxy-2-alkylquinolines (HAQs) family molecules produced by $B$. thailandensis [44]. It has been shown to function as an ionophore, to disrupt proton motive force, and to inhibit pyrimidine biosynthesis in Escherichia coli [45]. Rhamnolipids are well studied in P. aeruginosa [46] and the antimicrobial and antibiofilm activities of rhamnolipids have been previously characterized [47-49]. Interestingly, rhamnose is used for the synthesis of cell wall antigen rhamnoseglucose polysaccharide (RGP) and genetic ablation of either rhamnose biosynthesis gene $r m l D$ and rhamnoseglucose polysaccharide gene $\operatorname{rgp} G$ in $S$. mutans severely affects biofilm formation and cell wall turgor [50]. While anabolic pathways for rhamnose biosynthesis have been described, catabolic pathways for rhamnose degradation have yet to be described in S. mutans. It's possible that OMVs present high concentrations of unusable rhamnose in the form of rhamnolipids which alters RGP synthesis and subsequent biofilm formation. Current studies are underway to investigate the impact of OMVs on rhamnose availability and utilization in S. mutans. Interestingly, HMNQ and rhamnolipid alone or in combination were less effective than intact OMVs in disrupting $S$. mutans biofilms. This may be a consequence of concentration or could indicate that OMVs are better able to penetrate the biofilm. In support of the latter explanation, the efficacy of gentamicin against $S$. mutans biofilms was enhanced when the antibiotic was co-delivered with OMVs. This corroborates previous work that demonstrated a synergistic bactericidal effect of gentamicincontaining $P$. aeruginosa OMVs $[30,32]$. Together, our results indicate that OMVs derived from certain bacteria may be a viable adjunct therapy to enhance the effectiveness of antibiotics against bacterial biofilms. They could also be used in conjunction with other new antibiofilm therapeutics, such as recently described antimicrobial peptides D-CONGA and GH-12 that display antibiofilm activities [51, 52].

S. mutans forms one of the most robust biofilms in nature. The ability of bacterial-derived OMVs to inhibit and disrupt pre-formed S. mutans biofilms and to enhance antibiotic efficacy are compelling findings. These results suggest that vesicle-based strategies could lead to effective antibiofilm treatments. Compared to other nanoparticles used in clinical or industrial applications, naturally-derived OMVs may provide certain advantages in terms of lipid composition and cargo packaging. Studies characterizing phospholipids in $P$. aeruginosa OMVs showed a higher membrane rigidity of the vesicles compared to their bacterial cell outer membrane, which makes them more resistant to environmental perturbation [22]. OMVs are relatively stable at room temperature and resistant to freeze-thaw cycles, which makes them suitable for lyophilization and confers a broad array of applications [53]. Furthermore, bacterial secretory cargo is protected from degradation in the environment by selective packaging into OMVs [53]. Through selective culturing methods or genetic engineering, OMVs could be enriched with specific cargo that could work synergistically against different microbial species and complex biofilms. For clinical applications, careful consideration must be given to the presence of endotoxin in OMVs derived from bacterial species with highly inflammatory lipid A moieties [54]. Our work suggests that the soil bacterium B. thailandensis which possesses a weakly stimulatory lipid A secretes multiple antimicrobial agents through OMVs that target diverse microbes. Future studies could evaluate OMV genetic modifications to lower their toxicity while improving their antimicrobial potency and specificity.

\section{Conclusions}

Bacterial biofilms associated with human diseases, such as dental plaque caused by $S$. mutans, can be very difficult to eradicate. Here we used wellestablished $S$. mutans biofilm models combined with imaging and COMSTAT computer program analysis to study the antibiofilm activity of bacterial-derived outer membrane vesicles. We demonstrate the remarkable ability of OMVs to disrupt S. mutans biofilms and to enhance the efficacy of a co-delivered antibiotic. OMVs represent a promising microbialderived product for the treatment or inhibition of biofilm-forming species. 


\section{Methods}

\section{Bacterial Strains and Growth Conditions}

B. thailandensis strain E264 and S. mutans strains Clarke and UA159 (low passage isolate) were obtained from ATCC. S. mutans OMZ175 is a low passage clinical isolate that can invade epithelial cells (kindly provided by Dr. Tom Wen, LSU School of Dentistry). $B$. thailandensis was propagated in lysogeny broth (LB) and incubated at $37{ }^{\circ} \mathrm{C}$ with $233 \mathrm{rpm}$ oscillation. S. mutans was cultured in brain heart infusion broth (BHI), while solid medium was made by adding $1.5 \%$ (wt/vol) agar. $S$. mutans cultures were maintained at $37{ }^{\circ} \mathrm{C}$ in an aerobic chamber containing $5 \% \mathrm{CO}_{2}$ under static conditions.

\section{OMV Purification}

For OMV preparation, B. thailandensis E264 was grown in $3 \mathrm{~L} \mathrm{LB}$ broth at $37^{\circ} \mathrm{C}$ until late-log-phase $(18 \mathrm{~h})$. The intact bacteria were pelleted by centrifugation (Thermo Scientific, Sorvall RC5C plus) at 6,000. $g$ for $60 \mathrm{~min}$ at $4{ }^{\circ} \mathrm{C}$, and the supernatant was removed and filtered through a $0.22 \mu \mathrm{m}$ polyethersulfone (PES) filter (Millipore) to remove any remaining bacteria or large bacterial fragments. To ensure the supernatant was free of viable bacteria, one milliliter of filtered supernatant was streaked onto Pseudomonas isolation agar and incubated for $48 \mathrm{~h}$ at $37^{\circ} \mathrm{C}$. The OMVs were precipitated by slowly adding solid ammonium sulfate while stirring gently until a molarity of 1.5 was reached. OMVs were allowed to precipitate overnight at $4{ }^{\circ} \mathrm{C}$ before being harvested by centrifugation at $11,000 \cdot g$ for $45 \mathrm{~min}$ at $4{ }^{\circ} \mathrm{C}$. The resulting pellet, consisting of crude vesicles, was resuspended with $8 \mathrm{~mL} 60 \%$ sucrose in $30 \mathrm{mM}$ Tris- $\mathrm{HCl} \mathrm{pH}$ 8.0 (wt/vol), which was filter sterilized through a $0.22 \mu \mathrm{m}$ PES filter and layered at the bottom of a centrifuge tube. A sucrose gradient was prepared in centrifuge bottles by slowly layering $5 \mathrm{~mL} 55 \%, 5 \mathrm{~mL} 50 \%, 4 \mathrm{~mL}$ $45 \%, 4 \mathrm{~mL} 40 \%$, and $4 \mathrm{~mL} 35 \%$ sucrose in $30 \mathrm{mM}$ Tris$\mathrm{HCl} \mathrm{pH} 8.0$ over $4 \mathrm{~mL}$ of the crude OMV preparation. The sucrose gradient with crude OMVs was ultracentrifuged (Beckman Coulter, Optima XL-100 K) at 200,000. $g$ for $3 \mathrm{~h}$ at $4{ }^{\circ} \mathrm{C}$. Equal $3 \mathrm{~mL}$ fractions were removed sequentially from the top and stored at $4{ }^{\circ} \mathrm{C}$. To ensure the purity of the fraction, $200 \mu \mathrm{L}$ of each was precipitated with $20 \%$ Tri-chloroacetic acid (TCA) and washed twice with acetone. The resulting protein pellets were run on an SDS-PAGE gel (4-20\%, Bio-Rad). The final OMV preparation was recovered by pooling the purest fractions in $30 \mathrm{mM}$ Tris- $\mathrm{HCl} \mathrm{pH} 8.0$ followed by ultracentrifugation at $200,000 \cdot g$ for $19 \mathrm{~h}$ at $4{ }^{\circ} \mathrm{C}$. The resulting pellet, containing purified OMVs, was resuspended in Hyclone $^{\mathrm{Tm}}$ sterile cell culture water (GE LifeSciences) and quantified using a Bradford protein assay as we previously described [35].

\section{Bacterial Susceptibility Assays}

The antimicrobial activity of $B$. thailandensis OMVs was confirmed with a Kirby Bauer-like method. Briefly, a fresh culture of $S$. mutans was streaked heavily onto an agar plate, and $10 \mu \mathrm{g}$ OMVs (adjusted to $10 \mu \mathrm{L}$ with PBS) from each preparation were spotted directly onto the plate, using $10 \mu \mathrm{L} \mathrm{PBS}$ as negative control. The plate was incubated at $37{ }^{\circ} \mathrm{C}$ in an aerobic chamber containing $5 \% \mathrm{CO}_{2}$ under static conditions for up to $48 \mathrm{~h}$ at which time the plates were examined for growth inhibition.

\section{Growth Inhibition Assay}

The ability of OMVs, HMNQ, or rhamnolipid to inhibit the growth of $S$. mutans was examined using a growth inhibition assay. HMNQ and rhamnolipid were purified from $B$. thailandensis OMVs at greater than $90 \%$ purity as we previously described [35]. For testing OMVs, $S$. mutans were cultured overnight in $5 \mathrm{~mL}$ BHI broth at $37{ }^{\circ} \mathrm{C}$. The suspension was further diluted in BHI broth and added to a 96-well plate (Costar) at $80 \mu \mathrm{L} /$ well followed by treatments with $20 \mu \mathrm{L}$ of PBS, native OMVs, or heat-inactivated OMVs at the same concentration. Heat inactivation of OMVs was achieved by incubation on a heat block at $80{ }^{\circ} \mathrm{C}$ for $2 \mathrm{~h}$. For HMNQ and rhamnolipid, the purified compounds were dissolved in $\mathrm{MeOH}$ and added to a 96-well plate to a final concentration of $100 \mu \mathrm{M} H M N Q$, or $64 \mu \mathrm{g} / \mathrm{mL}$ rhamnolipid (based on previous dose determinations) and allowed to completely evaporate as previously described [35]. The overnight culture of $S$. mutans was diluted 1:1000 in BHI broth and added at $100 \mu \mathrm{L} /$ well into a 96-well plate after evaporation. Optical density at $600 \mathrm{~nm}$ was monitored until the culture reached stationary phase.

\section{Planktonic and Biofilm Antimicrobial Assays}

For planktonic cultures, S. mutans was grown overnight in $5 \mathrm{~mL}$ BHI broth without sucrose at $37{ }^{\circ} \mathrm{C}$ and $5 \%$ $\mathrm{CO}_{2}$ under static conditions. One-milliliter cell suspensions were centrifuged at $3,500 \cdot g$ for $10 \mathrm{~min}$. S. mutans biofilm was induced using a modified protocol from previously published studies $[55,56]$. Briefly, biofilms of $S$. mutans were grown on rectangular microscope coverslips in a semi-defined biofilm medium with glucose (18 $\mathrm{mM})$ and sucrose (2 mM) (BMGS) for 3 days at $37{ }^{\circ} \mathrm{C}$ and $5 \% \mathrm{CO}_{2}$ under static conditions. The biofilm

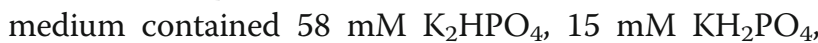
$10 \mathrm{mM}\left(\mathrm{NH}_{4}\right)_{2} \mathrm{SO}_{4}, 35 \mathrm{mM} \mathrm{NaCl}, 0.0001 \%$ (wt/vol) $\mathrm{FeCl}_{3} \cdot 6 \mathrm{H}_{2} \mathrm{O}$ and $0.2 \%$ (wt/vol) casamino acids (pH 7.4), and was supplemented with vitamins $(0.04 \mathrm{mM}$ nicotinic acid, $0.1 \mathrm{mM}$ pyridoxine $\mathrm{HCl}, 0.01 \mathrm{mM}$ pantothenic acid, $1 \mu \mathrm{M}$ riboflavin, $0.3 \mu \mathrm{M}$ thiamin $\mathrm{HCl}$, and $0.05 \mu \mathrm{M}$ d-biotin), amino acids (4 $\mathrm{mM}$ l-glutamic acid, $1 \mathrm{mM} \mathrm{l-}$ arginine $\mathrm{HCl}, 1.3 \mathrm{mM}$ l-cysteine $\mathrm{HCl}$, and $0.1 \mathrm{mM} \mathrm{l-}$ tryptophan), and $2 \mathrm{mM} \mathrm{MgSO}_{4} \cdot 7 \mathrm{H}_{2} \mathrm{O}$ [57-59]. The 
coverslips were vertically submerged in the culture medium, which was replaced daily. After 3 days, biofilms adhered to the glass surface were harvested by scraping off the coverslip and dispersing into $10 \mathrm{~mL}$ PBS. Onemilliliter cell suspensions were centrifuged at $3,500 \cdot g$ for $10 \mathrm{~min}$. Cell pellets of planktonic and biofilmassociated bacterial cells were resuspended with $300 \mu \mathrm{L}$ of 50 or $100 \mu \mathrm{g} / \mathrm{mL}$ OMVs, $800 \mu \mathrm{g} / \mathrm{mL}$ gentamicin, or PBS, respectively, followed by incubation at $37{ }^{\circ} \mathrm{C}$ and $5 \%$ $\mathrm{CO}_{2}$ [60]. At $0,3,6$, and $24 \mathrm{~h}, 70 \mu \mathrm{L}$ of each cell suspension was mixed with $630 \mu \mathrm{L}$ PBS and sonicated at 20 watts for $20 \mathrm{~s}$. The sonicated cell suspensions were then serially diluted and plated for colony-forming units (CFU).

\section{Biofilm Assay and Confocal Microscopy}

S. mutans was cultured overnight in BHI and diluted 1: 10 in BMGS. Biofilms were cultured statically in uncoated 8-well chamberslides at $37{ }^{\circ} \mathrm{C}$, with medium changed daily. To examine the antibiofilm activity of native OMVs, three-day biofilms of $S$. mutans were treated with 10,50 , or $100 \mu \mathrm{g} / \mathrm{mL}$ OMVs, or PBS for another $24 \mathrm{~h}$. To examine the antibiofilm activity of heatinactivated OMVs, one-day biofilms of $S$. mutans were treated with PBS, $100 \mu \mathrm{g} / \mathrm{mL}$ heat-inactivated OMVs or native OMVs for another $24 \mathrm{~h}$. To examine the antibiofilm activity of HMNQ and rhamnolipid, one-day biofilms of $S$. mutans were treated with PBS, $200 \mu \mathrm{g} / \mathrm{mL}$ rhamnolipid, $300 \mu \mathrm{M} \mathrm{HMNQ}$, or a combination of $200 \mu \mathrm{g} / \mathrm{mL}$ rhamnolipid with $300 \mu \mathrm{M}$ HMNQ for another $1.5 \mathrm{~h}$. HMNQ and rhamnolipid were purified from B. thailandensis OMVs with above $90 \%$ purity as previously described [35]. Biofilms were then stained with LIVE/DEAD BacLight fluorescent dye (SYTO 9/propidium iodide) (Invitrogen) and imaged on a Zeiss LSM 700 microscope with a $40 x$ oil objective. Confocal $z$ stacks and simulated $x y z$ three-dimensional images were generated using Zeiss' Zen 10.0 software. Seven to ten image stacks were acquired from random positions within each well in order to cover a representative area of $200,000 \mu \mathrm{m}^{2}$ of the total biofilm [41, 61]. For each $z$ stack, images were acquired at $1.0 \mu \mathrm{m}$ intervals and analyzed using COMSTAT 2.0 [41, 62].

\section{Field Emission Scanning Electron Microscopy}

S. mutans biofilms were grown on hydroxyapatite (HA) discs placed horizontally in 24-well microtiter plates as previously described [63-65]. Briefly, overnight bacterial cultures were grown in BHI and diluted 1:10 in BMGS. Two milliliters of the diluted culture were added to each well with HA disc. After incubating for three days at $37{ }^{\circ} \mathrm{C}$ in a $5 \% \mathrm{CO}_{2}$ aerobic atmosphere with medium changed daily, the HA discs were transferred into wells with PBS, $50 \mu \mathrm{g} / \mathrm{mL}$, or $100 \mu \mathrm{g} / \mathrm{mL}$ OMVs for another $24 \mathrm{~h}$. The HA discs were then washed with PBS and fixed in $2.5 \%$ glutaraldehyde overnight at $4{ }^{\circ} \mathrm{C}$. The fixed samples were dehydrated using increasing concentrations of ethanol, and desiccated with $\mathrm{CO}_{2}$ critical point drying. The samples were coated with carbon before imaging. Scanning electron microscopy (SEM) was performed with a Hitachi S-4800 high-resolution scanning electron microscope.

\section{Minimum Inhibitory Concentration Assays}

Minimum inhibitory concentrations (MIC) of gentamicin cooperatively with or without OMVs for biofilm cells (MIC-B) and planktonic cells (MIC-P) were measured as previously described $[60,66]$. For MIC-B, overnight $S$. mutans culture was adjusted to an $\mathrm{OD}_{600}$ of 0.5 and then diluted 1:1000 in BMGS. The bacterial suspension was added into a 96-well plate at $80 \mu \mathrm{L} /$ well and incubated for $24 \mathrm{~h}$ at $37{ }^{\circ} \mathrm{C}$ and $5 \% \mathrm{CO}_{2}$. Pre-formed biofilms were then washed once with PBS and treated with a 2-fold serial dilution of gentamicin starting at $800 \mu \mathrm{g} /$ $\mathrm{mL}$, with or without $5,10,20 \mu \mathrm{g} / \mathrm{mL}$ OMVs for another $24 \mathrm{~h}$. The treated biofilms were then washed with PBS to remove the treatments. To account for the detachment of viable cells within biofilms, fresh BHI was added into each well and incubated for $24 \mathrm{~h}$. $\mathrm{OD}_{600}$ of the supernatant was measured before and after the 24-hour incubation. For MIC-P, overnight $S$. mutans culture was adjusted to an $\mathrm{OD}_{600}$ of 0.5 and then diluted 1:1000 in BHI. Eighty microliters of cell suspension were added to the wells of the 96-well plates. Twenty microliters of serial 2-fold dilutions of gentamicin $(5 x)$ were added in each well with the final concentrations ranging from 0.04 to $40 \mu \mathrm{g} / \mathrm{mL}$. $\mathrm{OD}_{600}$ was measured before and after the 24-hour incubation at $37{ }^{\circ} \mathrm{C}$ and $5 \% \mathrm{CO}_{2}$. All experiments included three biological replicates and were independently repeated for three times.

\section{Statistical Analysis}

Pairs of independent samples were compared with twosample t-tests. Multiple comparisons were down with one-factor ANOVA. Pairs of curves were compared using a Chi-squared test [67]. This test enables calculation of single $\mathrm{p}$-value for the null hypothesis that any two arbitrary curves were sampled from the same parent population. When multiple curves were compared, the Bonferroni correction for multiple comparisons was used to modify the cutoff for statistical significance [67].

\section{Abbreviations}

OMV: Outer membrane vesicle; EPS: Extracellular polymeric substance; LPS: Lipopolysaccharide; HMNQ: 4-hydroxy-3-methyl-2-(2-non-enyl)-quinoline; BMGS: Biofilm medium containing glucose and sucrose; CFU: Colony-forming unit; PI: Propidium iodide; HA: Hydroxyapatite; SEM: Scanning electron microscopy; eDNA: Extracellular DNA; MIC: Minimal inhibitory concentration; HAQs: 4-hydroxy-2-alkylquinolines; RGP: Rhamnose-glucose polysaccharide; LB: Lysogeny broth; BHI: Brain heart infusion broth; PES: Polyethersulfone; TCA: Tri-chloroacetic acid 


\section{Appendix}

\section{Acknowledgements}

We thank Jibao He, supervisor of the Microscopy Lab at Tulane University Coordinated Instrument Facility, for assistance with electron microscopy. We thank Dr. Tom Wen, LSU School of Dentistry, for providing S. mutans low passage isolates.

\section{Authors' contributions}

The contributions of the authors are as follows: Conceptualization, Y.W., J.B. and L.M.; methodology, Y.W., J.B.; software, W.W. and L.M.; validation, Y.W. and L.M.; formal analysis, Y.W. and W.W.; investigation, Y.W., J.H., S.B.; resources, J.B., J.F., W.W. and L.M.; data curation, Y.W.; writing —original draft preparation, Y.W.; writing-review and editing, Y.W., J.H. S.B. K.H. J.B. and L.M. visualization, Y.W. and K.H. supervision, K.H., W.W., J.F., J.B. and L.M.; project administration, L.M.; funding acquisition, L.M. All authors have read and agreed to the published version of the manuscript.

\section{Funding}

This research was funded by Tulane University Carol Lavin Bernick and Committee on Research grants to L.M.

\section{Availability of data and materials}

The datasets used and/or analyzed during the current study are available from the corresponding author upon reasonable request.

\section{Declarations}

\section{Ethics approval and consent to participate}

Not applicable.

\section{Consent to publication}

Not applicable.

\section{Competing interests}

The authors declare no conflict of interest.

\section{Author details}

'Department of Microbiology and Immunology, Tulane University School of Medicine, 1430 Tulane Ave., SL-38, LA 70112-2699 New Orleans, USA. ${ }^{2}$ Department of Biochemistry and Molecular Biology, Tulane University School of Medicine, New Orleans, LA, USA. ${ }^{3}$ Department of Medicine, Tulane University School of Medicine, New Orleans, LA, USA.

\section{Received: 10 May 2021 Accepted: 13 August 2021}

\section{Published online: 24 August 2021}

\section{References}

1. $\mathrm{NIH}$. 2002. Research on microbial biofilms. https://grants.nih.gov/grants/ guide/pa-files/pa-03-047.html. Accessed

2. Davies D. 2003. Understanding biofilm resistance to antibacterial agents. Nat Rev Drug Discov 2:114-22

3. Mihai MM, Holban AM, Giurcaneanu C, Popa LG, Oanea RM, Lazar V, Chifiriuc MC, Popa M, Popa MI. 2015. Microbial biofilms: impact on the pathogenesis of periodontitis, cystic fibrosis, chronic wounds and medical device-related infections. Curr Top Med Chem 15:1552-76.

4. Flemming HC, Wingender J, Szewzyk U, Steinberg P, Rice SA, Kjelleberg S. 2016. Biofilms: an emergent form of bacterial life. Nat Rev Microbiol 14:563-75.

5. Stewart PS. 1998. A review of experimental measurements of effective diffusive permeabilities and effective diffusion coefficients in biofilms. Biotechnol Bioeng 59:261-72.

6. Mulcahy LR, Burns JL, Lory S, Lewis K. 2010. Emergence of Pseudomonas aeruginosa strains producing high levels of persister cells in patients with cystic fibrosis. J Bacteriol 192:6191-9.

7. Fisher RA, Gollan B, Helaine S. 2017. Persistent bacterial infections and persister cells. Nat Rev Microbiol 15:453-464.

8. Costerton JW, Stewart PS, Greenberg EP. 1999. Bacterial biofilms: a common cause of persistent infections. Science 284:1318-22.

9. Stewart PS, Costerton JW. 2001. Antibiotic resistance of bacteria in biofilms. Lancet 358:135-8.
10. Gunn JS, Bakaletz LO, Wozniak DJ. 2016. What's on the Outside Matters: The Role of the Extracellular Polymeric Substance of Gram-negative Biofilms in Evading Host Immunity and as a Target for Therapeutic Intervention. J Biol Chem 291:12538-46.

11. Peng X, Zhang Y, Bai G, Zhou X, Wu H. 2016. Cyclic di-AMP mediates biofilm formation. Mol Microbiol 99:945-59.

12. Pleszczynska M, Wiater A, Janczarek M, Szczodrak J. 2015. (1->3)-alpha-DGlucan hydrolases in dental biofilm prevention and control: A review. Int J Biol Macromol 79.761-78.

13. Fleming D, Chahin L, Rumbaugh K. 2017. Glycoside Hydrolases Degrade Polymicrobial Bacterial Biofilms in Wounds. Antimicrob Agents Chemother 61.

14. Brackman G, Coenye T. 2015. Quorum sensing inhibitors as anti-biofilm agents. Curr Pharm Des 21:5-11.

15. DiGiandomenico A, Warrener P, Hamilton M, Guillard S, Ravn P, Minter R, Camara MM, Venkatraman V, Macgill RS, Lin J, Wang Q, Keller AE, Bonnell JC, Tomich M, Jermutus L, McCarthy MP, Melnick DA, Suzich JA, Stover CK. 2012. Identification of broadly protective human antibodies to

Pseudomonas aeruginosa exopolysaccharide Psl by phenotypic screening. J Exp Med 209:1273-87.

16. Flores-Mireles AL, Pinkner JS, Caparon MG, Hultgren SJ. 2014. EbpA vaccine antibodies block binding of Enterococcus faecalis to fibrinogen to prevent catheter-associated bladder infection in mice. Sci Transl Med 6:254ra127.

17. Koo H, Allan RN, Howlin RP, Stoodley P, Hall-Stoodley L. 2017. Targeting microbial biofilms: current and prospective therapeutic strategies. Nat Rev Microbiol 15:740-755.

18. Haurat MF, Aduse-Opoku J, Rangarajan M, Dorobantu L, Gray MR, Curtis MA, Feldman MF. 2011. Selective sorting of cargo proteins into bacterial membrane vesicles. Journal of biological chemistry 286:1269-1276.

19. Baumgarten T, Sperling S, Seifert J, von Bergen M, Steiniger F, Wick LY, Heipieper HJ. 2012. Membrane vesicle formation as a multiple-stress response mechanism enhances Pseudomonas putida DOT-T1E cell surface hydrophobicity and biofilm formation. Appl Environ Microbiol 78:6217-24.

20. Mashburn-Warren L, Howe J, Garidel P, Richter W, Steiniger F, Roessle M, Brandenburg K, Whiteley M. 2008. Interaction of quorum signals with outer membrane lipids: insights into prokaryotic membrane vesicle formation. Molecular Microbiology 69:491-502.

21. Bonnington KE, Kuehn MJ. 2014. Protein selection and export via outer membrane vesicles. Biochim Biophys Acta 1843:1612-9.

22. Tashiro Y, Inagaki A, Shimizu M, Ichikawa S, Takaya N, Nakajima-Kambe T, Uchiyama H, Nomura N. 2011. Characterization of phospholipids in membrane vesicles derived from Pseudomonas aeruginosa. Biosci Biotechnol Biochem 75:605-7.

23. Nieves W, Asakrah S, Qazi O, Brown KA, Kurtz J, Aucoin DP, McLachlan JB, Roy CJ, Morici LA. 2011. A naturally derived outer-membrane vesicle vaccine protects against lethal pulmonary Burkholderia pseudomallei infection. Vaccine 29:8381-9.

24. Sjostrom AE, Sandblad L, Uhlin BE, Wai SN. 2015. Membrane vesiclemediated release of bacterial RNA. Sci Rep 5:15329.

25. Dorward DW, Garon CF. 1990. DNA Is Packaged within Membrane-Derived Vesicles of Gram-Negative but Not Gram-Positive Bacteria. Appl Environ Microbiol 56:1960-2

26. Mashburn-Warren LM, Whiteley M. 2006. Special delivery: vesicle trafficking in prokaryotes. Mol Microbiol 61:839-46.

27. Schooling SR, Beveridge TJ. 2006. Membrane vesicles: an overlooked component of the matrices of biofilms. J Bacteriol 188:5945-57.

28. Vasilyeva NV, Tsfasman IM, Suzina NE, Stepnaya OA, Kulaev IS. 2008. Secretion of bacteriolytic endopeptidase L5 of Lysobacter sp. XL1 into the medium by means of outer membrane vesicles. FEBS J 275:3827-35.

29. Berleman JE, Allen S, Danielewicz MA, Remis JP, Gorur A, Cunha J, Had MZ, Zusman DR, Northen TR, Witkowska HE, Auer M. 2014. The lethal cargo of Myxococcus xanthus outer membrane vesicles. Front Microbiol $5: 474$

30. Kadurugamuwa JL, Beveridge TJ. 1996. Bacteriolytic effect of membrane vesicles from Pseudomonas aeruginosa on other bacteria including pathogens: conceptually new antibiotics. J Bacteriol 178:2767-74.

31. Li Z, Clarke AJ, Beveridge TJ. 1998. Gram-negative bacteria produce membrane vesicles which are capable of killing other bacteria. J Bacteriol 180:5478-83.

32. MacDonald KL, Beveridge TJ. 2002. Bactericidal effect of gentamicin-induced membrane vesicles derived from Pseudomonas aeruginosa PAO1 on grampositive bacteria. Can J Microbiol 48:810-20. 
33. Baker S, Davitt C, Morici L. 2016. Gram-Negative Bacterial Outer Membrane Vesicles Inhibit Growth of Multidrug-Resistant Organisms and Induce Wound-Healing Cytokines. Open Forum Infectious Diseases 3.

34. Novem V, Shui G, Wang D, Bendt AK, Sim SH, Liu Y, Thong TW, Sivalingam SP, Ooi EE, Wenk MR, Tan G. 2009. Structural and biological diversity of lipopolysaccharides from Burkholderia pseudomallei and Burkholderia thailandensis. Clin Vaccine Immunol 16:1420-8.

35. Wang Y, Hoffmann JP, Chou C-W, Höner zu Bentrup K, Fuselier JA, Bitoun JP, Wimley WC, Morici LA. 2020. Burkholderia thailandensis outer membrane vesicles exert antimicrobial activity against drug-resistant and competitor microbial species. Journal of Microbiology doi:https://doi.org/10.1007/s122 75-020-0028-1

36. Petersen PE, Ogawa H. 2016. Prevention of dental caries through the use of fluoride - the WHO approach. Community Dental Health 33:66-68.

37. Loesche WJ. 1986. Role of Streptococcus mutans in human dental decay. Microbiol Rev 50:353-80.

38. Koo H, Xiao J, Klein Ml. 2009. Extracellular polysaccharides matrix-an often forgotten virulence factor in oral biofilm research. Int J Oral Sci 1:229-34.

39. Nomura R, Nakano K, Nemoto H, Fujita K, Inagaki S, Takahashi T, Taniguchi K, Takeda M, Yoshioka H, Amano A. 2006. Isolation and characterization of Streptococcus mutans in heart valve and dental plaque specimens from a patient with infective endocarditis. Journal of medical microbiology 55 : 1135-1140.

40. Lemos JA, Quivey RG, Jr., Koo H, Abranches J. 2013. Streptococcus mutans: a new Gram-positive paradigm? Microbiology 159:436-45.

41. Heydorn A, Nielsen AT, Hentzer M, Sternberg C, Givskov M, Ersboll BK, Molin S. 2000. Quantification of biofilm structures by the novel computer program COMSTAT. Microbiology 146 (Pt 10):2395-407.

42. Snyder RJ, Wilkowske CJ, Washington JA. 1975. Bactericidal activity of combinations of gentamicin with penicillin or clindamycin against Streptococcus mutans. Antimicrobial Agents and Chemotherapy 7:333-335.

43. Vollmer W, Blanot D, de Pedro MA. 2008. Peptidoglycan structure and architecture. FEMS Microbiol Rev 32:149-67.

44. Vial L, Lepine F, Milot S, Groleau MC, Dekimpe V, Woods DE, Deziel E. 2008 Burkholderia pseudomallei, B. thailandensis, and B. ambifaria produce 4hydroxy-2-alkylquinoline analogues with a methyl group at the 3 position that is required for quorum-sensing regulation. J Bacteriol 190:5339-52.

45. Wu Y, Seyedsayamdost MR. 2017. Synergy and Target Promiscuity Drive Structural Divergence in Bacterial Alkylquinolone Biosynthesis. Cell Chem Biol 24:1437-1444.e3.

46. Abdel-Mawgoud AM, Lepine F, Deziel E. 2010. Rhamnolipids: diversity of structures, microbial origins and roles. Appl Microbiol Biotechnol 86:1323-36.

47. De Rienzo MA, Martin PJ. 2016. Effect of Mono and Di-rhamnolipids on Biofilms Pre-formed by Bacillus subtilis BBK006. Curr Microbiol 73:183-9.

48. Elshikh M, Funston S, Chebbi A, Ahmed S, Marchant R, Banat IM. 2017. Rhamnolipids from non-pathogenic Burkholderia thailandensis E264: Physicochemical characterization, antimicrobial and antibiofilm efficacy against oral hygiene related pathogens. N Biotechnol 36:26-36.

49. Vatsa P, Sanchez L, Clement C, Baillieul F, Dorey S. 2010. Rhamnolipid biosurfactants as new players in animal and plant defense against microbes. Int J Mol Sci 11:5095-108.

50. De A, Liao S, Bitoun JP, Roth R, Beatty WL, Wu H, Wen ZT. 2017. Deficiency of RgpG Causes Major Defects in Cell Division and Biofilm Formation, and Deficiency of LytR-CpsA-Psr Family Proteins Leads to Accumulation of Cell Wall Antigens in Culture Medium by Streptococcus mutans. Appl Environ Microbiol 83.

51. Jiang W, Wang Y, Luo J, Chen X, Zeng Y, Li X, Feng Z, Zhang L. 2020. Antimicrobial Peptide GH12 Prevents Dental Caries by Regulating Dental Plaque Microbiota. Appl Environ Microbiol 86.

52. Starr CG, Ghimire J, Guha S, Hoffmann JP, Wang Y, Sun L, Landreneau BN, Kolansky ZD, Kilanowski-Doroh IM, Sammarco MC, Morici LA, Wimley WC. 2020. Synthetic molecular evolution of host cell-compatible, antimicrobial peptides effective against drug-resistant, biofilm-forming bacteria. Proceedings of the National Academy of Sciences doi:https://doi.org/10.1 073/pnas.1918427117:201918427.

53. Alves NJ, Turner KB, Medintz IL, Walper SA. 2016. Protecting enzymatic function through directed packaging into bacterial outer membrane vesicles. Sci Rep 6:24866.

54. Gnopo YMD, Watkins HC, Stevenson TC, DeLisa MP, Putnam D. 2017. Designer outer membrane vesicles as immunomodulatory systems - Reprogramming bacteria for vaccine delivery. Adv Drug Deliv Rev 114:132-142.
55. de Queiroz VS, Ccahuana-Vasquez RA, Tedesco AF, Lyra L, Cury JA, Schreiber AZ. 2016. Influence of the Culture Medium in Dose-Response Effect of the Chlorhexidine on Streptococcus mutans Biofilms. Scientifica (Cairo) 2016: 2816812.

56. Koo H, Hayacibara MF, Schobel BD, Cury JA, Rosalen PL, Park YK, VaccaSmith AM, Bowen WH. 2003. Inhibition of Streptococcus mutans biofilm accumulation and polysaccharide production by apigenin and tt-farnesol. J Antimicrob Chemother 52:782-9.

57. Loo CY, Corliss DA, Ganeshkumar N. 2000. Streptococcus gordonii biofilm formation: identification of genes that code for biofilm phenotypes. J Bacteriol 182:1374-82.

58. Bitoun JP, Liao S, Yao X, Ahn SJ, Isoda R, Nguyen AH, Brady LJ, Burne RA, Abranches J, Wen ZT. 2012. BrpA is involved in regulation of cell envelope stress responses in Streptococcus mutans. Appl Environ Microbiol 78:2914-22.

59. Wen ZT, Burne RA. 2002. Functional genomics approach to identifying genes required for biofilm development by Streptococcus mutans. Appl Environ Microbiol 68:1196-203.

60. Nilsson M, Rybtke M, Givskov M, Hoiby N, Twetman S, Tolker-Nielsen T. 2016. The dlt genes play a role in antimicrobial tolerance of Streptococcus mutans biofilms. Int J Antimicrob Agents 48:298-304.

61. Korber D, Lawrence J, Hendry M, Caldwell D. 1993. Analysis of spatial variability within Mot + and Mot - Pseudomonas fluorescens biofilms using representative elements. Biofouling 7:339-358.

62. Vorregaard M. 2008. Comstat2-a modern 3D image analysis environment for biofilmsCiteseer

63. Bitoun JP, Nguyen AH, Fan Y, Burne RA, Wen ZT. 2011. Transcriptional repressor Rex is involved in regulation of oxidative stress response and biofilm formation by Streptococcus mutans. FEMS Microbiol Lett 320:110-7.

64. Wen ZT, Baker HV, Burne RA. 2006. Influence of BrpA on critical virulence attributes of Streptococcus mutans. J Bacteriol 188:2983-92.

65. Wen ZT, Suntharaligham P, Cvitkovitch DG, Burne RA. 2005. Trigger factor in Streptococcus mutans is involved in stress tolerance, competence development, and biofilm formation. Infect Immun 73:219-25.

66. Mah TF. 2014. Establishing the minimal bactericidal concentration of an antimicrobial agent for planktonic cells (MBC-P) and biofilm cells (MBC-B). J Vis Exp doi:https://doi.org/10.3791/50854:e50854

67. He L, Shobnam N, Wimley WC, Hristova K. 2011. FGFR3 heterodimerization in achondroplasia, the most common form of human dwarfism. J Biol Chem 286:13272-81.

\section{Publisher's Note}

Springer Nature remains neutral with regard to jurisdictional claims in published maps and institutional affiliations.

Ready to submit your research? Choose BMC and benefit from:

- fast, convenient online submission

- thorough peer review by experienced researchers in your field

- rapid publication on acceptance

- support for research data, including large and complex data types

- gold Open Access which fosters wider collaboration and increased citations

- maximum visibility for your research: over $100 \mathrm{M}$ website views per year

At BMC, research is always in progress.

Learn more biomedcentral.com/submission 